\title{
A RARE CASE OF A SOLITARY OSTEOCHONDROMA OF THE ILIAC WING: CASE REPORT
}

\author{
Tanvir Doomra', Abhijeet Kumar ${ }^{2}$ \\ ${ }^{1}$ Senior Resident, Department of Orthopaedics, Goa Medical College. \\ 2Senior Consultant, Department of Orthopaedics, District Hospital, Mapusa.
}

\section{ABSTRACT}

Osteochondromas, also known as exostoses are benign neoplasms, which arise from small cartilage nodules within the periosteum. They can be either pedunculated or sessile and are more common in the extremities, mostly around the knees. They rarely develop in bones like scapula, feet, hands and pelvis. Management of the lesion is by en-bloc extra-periosteal excision. This case is published for the rarity of location of the osteochondroma.

\section{CASE REPORT}

We present a case of 17-year male who came with a swelling in right groin since 1 year, which was diagnosed to be osteochondroma on clinical examination and radiological imaging. Excision biopsy was done as the patient wanted it to be removed for cosmetic purpose and confirmed it to be non-malignant osteochondroma. There has been no recurrence at 1 year of followup.

\section{CONCLUSION}

Thus osteochondroma of the pelvis should be kept in mind as a differential diagnosis when evaluating mass in pelvis. Also the se have to be removed when they pose cosmetic problems.

\section{KEYWORDS}

Ilium, Pelvis, Osteochondroma, Exostosis.

HOW TO CITE THIS ARTICLE: Doomra T, Kumar A. A rare case of a solitary osteochondroma of the iliac wing: case report. J. Evolution Med. Dent. Sci. 2016;5(15):732-735, DOI: 10.14260/jemds/2016/168

\section{INTRODUCTION}

Osteochondroma is the commonest of all benign bone tumours.[1] Most of osteochondromas are found around the knee and the most commonly involved site is the distal end of the femur.[2,3] Osteochondroma is a cartilage-capped bony protrusion on the external surface of the bone. Many osteochondromas are asymptomatic and are incidentally discovered on radiography.[4] Sarcomatous degeneration of an osteochondroma is less than $2 \% .{ }^{[5]}$ Pelvic ostechondromas are rare with an incidence of 5\%.[6] Ilium is a rare site for osteochondroma.[7] We report a case of symptomatic osteochondroma of the ilium in a 17-year-old boy, which was managed by en-bloc extra-periosteal resection with no recurrence at the end of one year.

\section{CASE PRESENTATION}

A 17-year-old male, student by occupation, presented with chief complaints of a swelling in the left iliac region for the last one year. This was a solitary, painless swelling which had grown in size over the last one year. Patient did not complain of similar swelling in any other part of the body. There was no history of fever, loss of appetite or loss of weight. There was no history of abdominal discomfort, pain, nausea or vomiting. The past medical history was insignificant. General and systemic examinations did not reveal any abnormality.

Financial or Other, Competing Interest: None.

Submission 07-01-2016, Peer Review 04-02-2016,

Acceptance 09-02-2016, Published 22-02-2016.

Corresponding Author:

Tanvir Doomra,

\#153, Gard, Goa Medical College,

Bambolim, Goa.

E-mail: dr_tanvirdoomra@hotmail.com

DOI: $10.14260 /$ jemds $/ 2016 / 168$
On local examination there was a solitary, globular swelling measuring $3 \times 3 \mathrm{~cm}$, arising from the posterior aspect of iliac crest. The skin overlying the swelling was normal. There was no local rise in temperature. The swelling was nontender, well defined, bony hard in consistency and continuous with the iliac crest (Figure 1). Regional lymph nodes were not enlarged. No gluteal muscle atrophy was noticed. The neurovascular status of the right lower limb was unremarkable. Examination of the ipsilateral and contralateral lower limb joints and spine was within normal limits. Haematological and serum biochemical tests were within normal limits.

The radiograph of the pelvis revealed a small globular swelling arising from the posterior aspect of the left iliac crest (Figure 2). CT scan of the pelvis revealed a localized bosselated mass arising from the posterior aspect of left iliac crest, not extending into the surrounding tissue (Figure 3). Due to financial constraints, MRI scan of the patient could not be performed. An ultrasound was hence requested to size the cartilage cap, which measured $3 \mathrm{~mm}$ in size. A provisional diagnosis of osteochondroma was made on the basis of clinical and radiological findings.

The condition, its prognosis and treatment were discussed at length with the patient and a decision to perform en-bloc resection of the tumour was taken in view of progressively increasing swelling and cosmetic concern. The patient was taken up for surgery under general anaesthesia in prone position. A linear incision measuring around $6 \mathrm{~cm}$ was taken along the length of the posterior third of the iliac crest centered over the swelling. The superficial cluneal nerves were identified and protected. A bosselated mass covered by periosteum was resected extra-periosteally in-toto (Figure 4). The specimen was continuous with the iliac bone, which was subsequently cleared off. 
The resected specimen demonstrated a bluish cartilaginous cap overlying the bony swelling (Figure 5). The specimen was sent for histopathological examination. Microscopy of the specimen showed no features of malignancy and columns of chondrocytes forming a cartilage cap underneath which were osteocytes forming bony trabeculae feature, characteristic of osteochondroma (Figure 6). Postoperative course of the patient was uneventful with no recurrence at end of one year of regular followup (Figure 7).

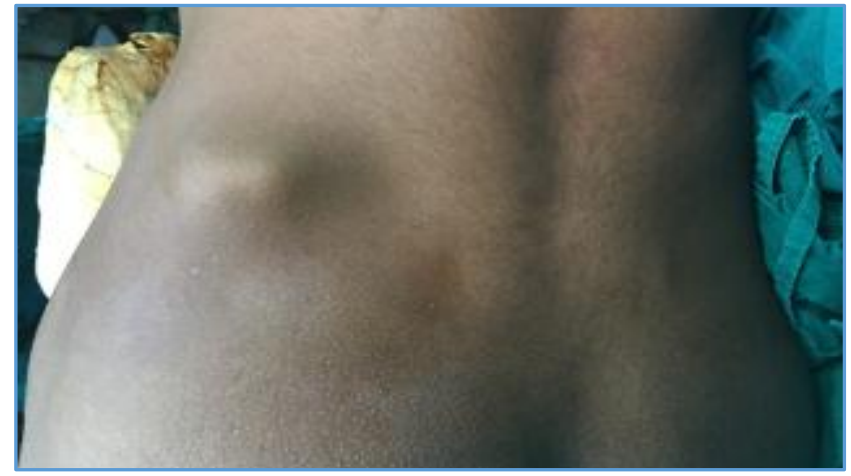

Fig. 1: Clinical photograph of the patient showing swelling arising from posterior aspect of left ilium

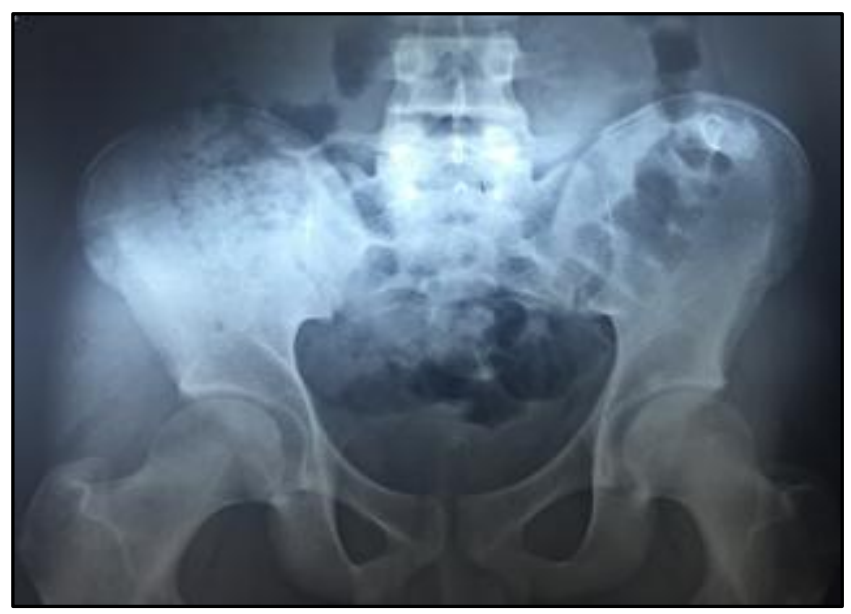

Fig. 2: AP radiograph of the pelvis showing a solitary sessile mass arising from left iliac bone

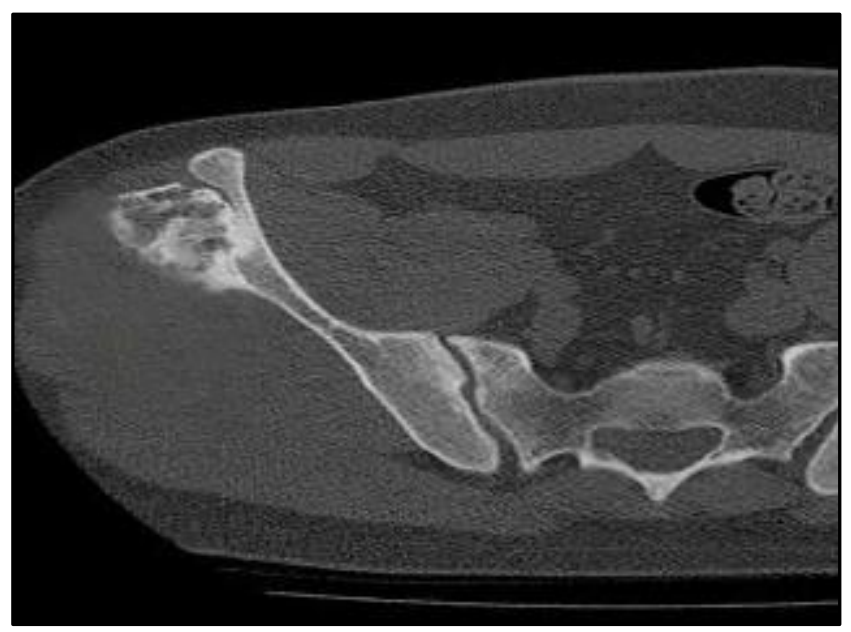

Fig. 3: CT scan of pelvis demonstrating a solitary, sessile, bosselated, benign mass with no cortical breakage suggestive of osteochondroma

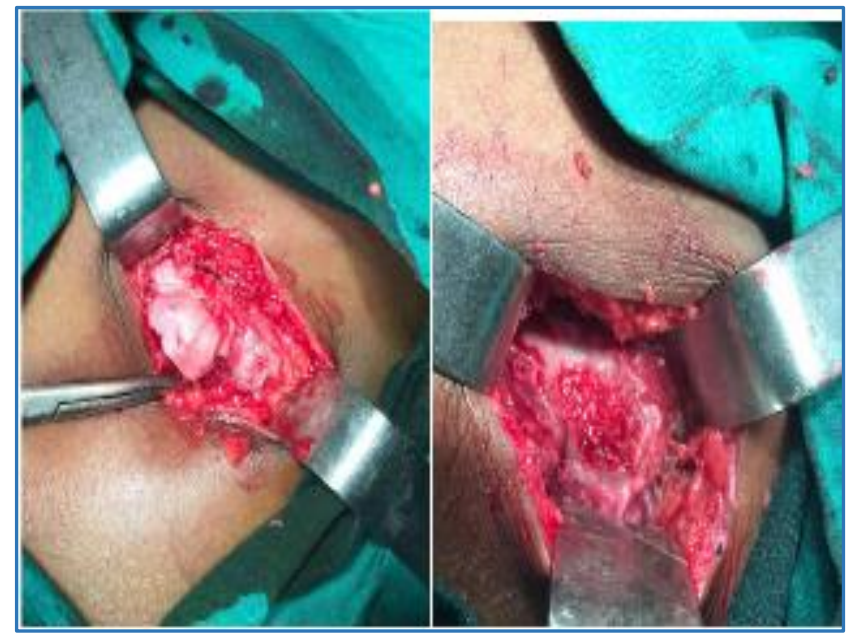

Fig. 4: Intraoperative photographs

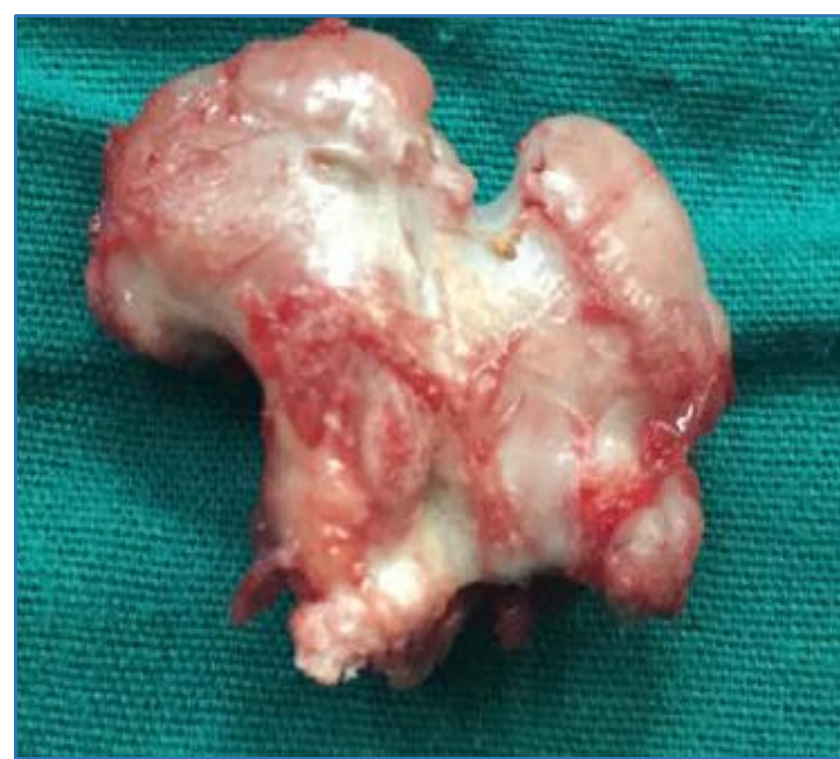

Fig. 5: Resected specimen covered by thin bluish cartilage cap

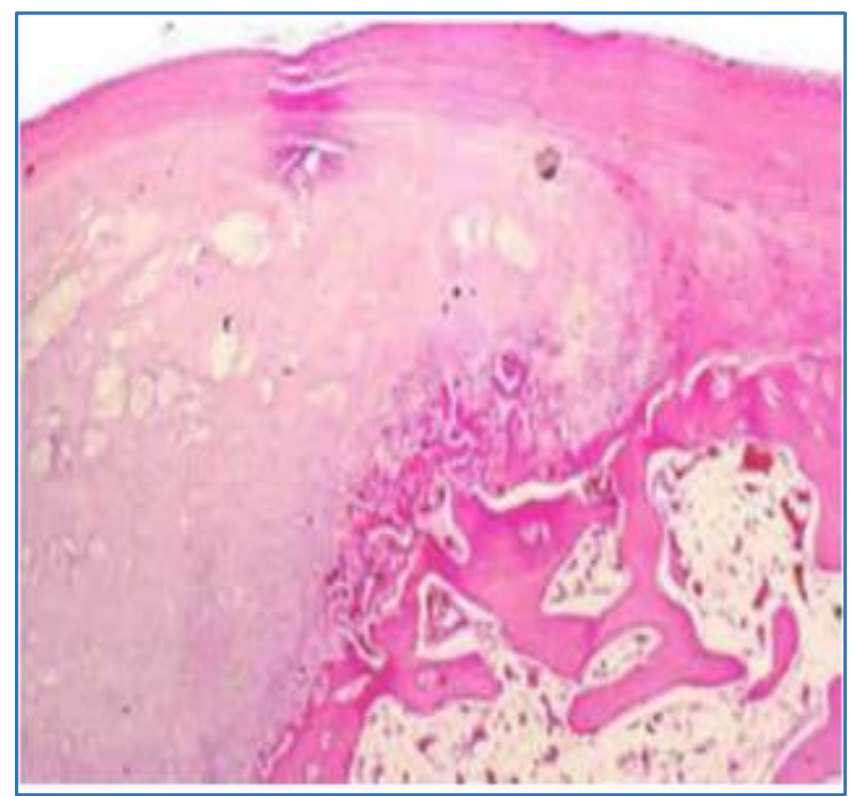

Fig. 6: Histopathological picture showing columns of chondrocytes forming a cartilage cap with osteocytes underneath forming bony trabeculae 


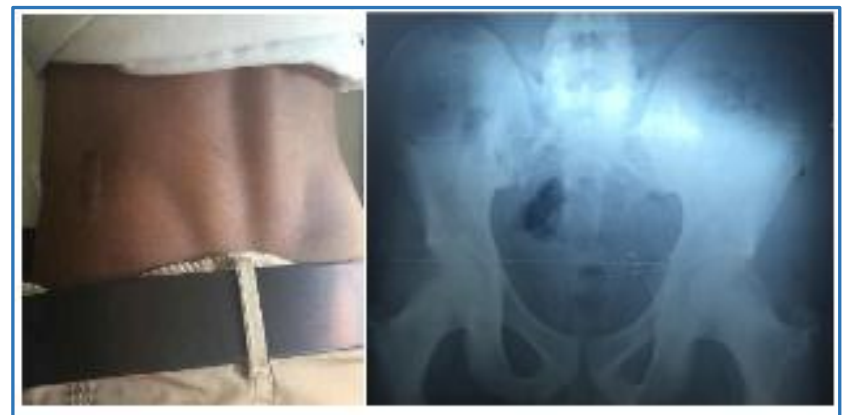

Fig. 7: Clinical and radiological photographs at 1 year of followup showing no recurrence

\section{DISCUSSION}

Osteochondromas, also known as exostoses account for $43.7 \%$ of all the bony neoplasms.[1] However, these are not true bone tumours since they represent developmental lesions of the bone.[8] Majority of the patients present within the second decade or earlier with a male:female ratio of 1.6-3.4:1.[9] Cytogenetic analysis has revealed that inactivation of both the copies of EXT 1 tumor suppressor gene is required for their development.[3,10] A typical osteochondroma begins as a small overgrowth of the cartilage at the edge of the physeal plate in which endochondral calcification occurs and it ultimately develops into a bony protuberance covered by a cartilaginous cap.

Its growth usually parallels that of the growth plate and ceases with skeletal maturity.[8] Some osteochondromas may also arise as a result of iatrogenic injury to the growth plate in the form of prior surgery or irradiation.[11,12] Osteochondromas may involve any bone that develops in the cartilage. Most frequently these occur in the long bones of lower extremity with a maximum predilection for distal femur.[8] Less commonly, they may also be seen in short tubular and flat bones.

Pelvic osteochondromas are rare. Most of the patients present with a painless bony swelling. Lesions from posterior part of the iliac crest can present with radiculopathy secondary to nerve root compression.[13,14,15] Large lesions from inner table of ilium or from iliac crest can have bowel and bladder symptoms or even major vessel compression with lower limb ischaemia.

Plain radiographs are often diagnostic, the most characteristic feature being the extension of the medullary canal of the parent bone into the osteochondroma. Radiologically, two distinct forms can be recognized, i.e. sessile and pedunculated, the latter being more common and accounting for $88.2 \%$ of the cases.[2] They have a classic mushroom shape with a narrow to broad stalk attaching the tumour to the parent bone.[4]

CT scan serves as a very good modality for demonstrating the cortical and medullary continuity and to evaluate for signs of malignancy. Ultrasound helps to determine the thickness of the cartilaginous cap, but MRI is the imaging modality of choice for evaluating the same. Normally, the cap is only a few millimeters thick in adults and any thickness more than $2 \mathrm{cms}$ should be viewed suspiciously. ${ }^{[8]}$

Definitive diagnosis is usually established on histopathological examination. The presence of cortical and cancellous bone, both of which are continuous with the corresponding components of the parent bone, covered by a hyaline cartilaginous cap is diagnostic.
Malignant transformation into secondary chondrosarcoma can be seen in about $1 \%$ of cases with solitary osteochondromas and $5 \%$ of cases with multiple hereditary exostoses. Sudden and rapid enlargement, continued growth after skeletal maturity and development of pain in an otherwise painless swelling are important clinical signs indicative of malignant transformation.

Most of the osteochondromas can be managed by observation alone. Surgical treatment in the form of en-bloc resection is usually indicated for pain, cosmetic reasons, neurovascular compromise, abnormal growth, skeletal deformity, decreased motion of the adjacent joint or in cases with evidence of malignant transformation.

In our patient, the swelling had increased in size over a period of one year and was cosmetically unappealing. Hence, we have considered surgical resection of the lesion in our patient. The base of the tumor was reached and en-bloc resection was performed with saucerization of the base of the tumour to ensure that no cartilage remnants are left behind. Recurrences after complete surgical resection are rare and are probably caused by failure to remove the entire cartilaginous cap. ${ }^{[8]}$

\section{CONCLUSION}

To conclude, osteochondroma of the pelvis should be kept in mind as a differential diagnosis when evaluating mass in pelvis. These have to be removed when they pose cosmetic problems.

\section{REFERENCES}

1. Baena-Ocampo Ldel C, Ramirez-Perez E, LinaresGonzalez LM, et al. Epidemiology of bone tumors in Mexico city: retrospective clinicopathologic study of 566 patients at a referral institution. Ann Diagn Pathol 2009 Feb;13(1):16-21.

2. Obalum DC, Eyesan SU, Ezembakwe ME, et al. Pattern of osteochondromas in Lagos, Nigeria. Nig Q J Hosp Med 2008;18:69-71.

3. Kitsoulis P, Galani V, Stefanaki K, et al. Osteochondromas: review of the clinical, radiological and pathological features. In Vivo 2008;22:633-46.

4. Unni KK, editor. Dahlin's Bone Tumors: General aspects and data on 11,087 cases. 5th ed. Philadelphia: Lippincott-Raven; 1996; p11-23.e clinical, radiological and pathological features. In Vivo 2008;22:633-46.

5. Robson AK, Kissin MW, Eltringham WK. Chondrosarcoma arising in an osteochondroma: an unusual cause of an abdominal mass. Eur J Surg Oncol 1990;16:60-2.

6. Kim WJ, Kim KJ, Lee SK, et al. Solitary pelvic osteochondroma causing L5 nerve root compression. Orthopedics 2009;32(12):922-924.

7. Sharma S, Kalsotra N, Gupta P, et al. Solitary osteochondroma of the ilium: a case report. The Internet Journal of Orthopedic Surgery, 2009;16(2).

8. Robert KS, Heck J: 20. In Campbell's Operative Orthopaedics. 2. 11th. S. Terry Canale JHB. Philadelphia: Mosby Elsevier; 2007;860-862.

9. Wodajo FM. Cartilage Lesions. In: III PT, Einhorn TA, Damron TA, editors. Oncology and Basic Science. 7th ed: Lippincott Williams \& Wilkins, 2008;132-5. 
10. Xiao CY, Wang J, Zhang SZ, et al. A novel deletion mutation of the EXT2 gene in a large Chinese pedigree with hereditary multiple exostosis. $\mathrm{Br}$ J Cancer 2001;85:176-81.

11. Cree AK, Hadlow AT, Taylor TK, et al. Radiation-induced osteochondroma in the lumbar spine. Spine (Phila $\mathrm{Pa}$ 1976). 1994;19:376-9.

12. DeSimone DP, Abdelwahab IF, Kenan S, et al. Case report 773. Radiation-induced osteochondroma of the ilium. Skeletal Radiol 1993; 22:135-7.
13. Kim WJ, Kim KJ, Lee SK, et al. Solitary pelvic osteochondroma causing L5 nerve root compression. Orthopedics 2009;32:922-4.

14. Larson J, O'Malley JE, Cohen TI. Case report: solitary pelvic osteochondroma presenting with L3 nerve root compression. Alaska Med 2002;44:35-7.

15. Trotter D, Zindrick M, Ibrahim K. An unusual presentation of an osteochondroma. Report of a case. J Bone Joint Surg Am 1984;66:299-301. 